\title{
Drug use as a coping style to social isolation by COVID-I 9 pandemic and its effects on the adherence to safety guidelines in Mexico
}

\author{
Diana Mejía', Alejandro Rodrigo Gutierrez-Trejo², Laurent Avila-Chauvet' ${ }^{1}$, Lynette Bonin ${ }^{3}$ \\ I Departamento de Psicología, Instituto Tecnológico de Sonora, Sonora, México \\ ${ }^{2}$ Centro de Estudios e Investigaciones en Comportamiento, Universidad de Guadalajara, Guadalajara, México \\ 3 Faculty of Arts, Department of Psychology, University of Manitoba, Manitoba, Canada
}

\begin{abstract}
ABCTRACT
Introduction: in response to the pandemic originated by COVID-19, governments placed in practice a series of safety guidelines recommended by the World Health Organization (WHO). In Mexico, one of the decisive actions to prevent the disease's spread was social isolation or lockdown. These rigorous proceedings could increase stress experience or other mental health disorders. One of the coping mechanisms used to avoid stress includes drug use. Objective: the study's goal was to evaluate the relationship between drug use (alcohol, tobacco, and cannabis) and adherence to safety guidelines. Method: the association between the variables was assessed with a series of surveys indicating adherence to safety guidelines and drug use, 475 Mexican participants (56.5\% females and $43.4 \%$ males) completed the study. Results: the results suggest that most participants had low drug abuse levels before and during social isolation. There was a significant decrease in tobacco, alcohol, and cannabis use in both females and males. Upon analyzing guideline adherence, low alcohol use correlated with the safety behavior scale, while tobacco and cannabis correlated with the preventive behavior scale. Discussion: the current Mexican sample had not used drugs to cope during social isolation.
\end{abstract}

Keywords: alcohol, cannabis, COVID-19, tobacco, drug use.

\begin{abstract}
RESUMEN
Introducción: en respuesta a la pandemia originada por el COVID-19, los gobiernos pusieron en práctica una serie de pautas de seguridad recomendadas por la Organización Mundial de la Salud (OMS). En México, una de las acciones decisivas para prevenir la propagación de la enfermedad fue el aislamiento social o confinamiento. Estos rigurosos procedimientos podrían incrementar los síntomas de estrés o trastornos mentales. Uno de los mecanismos de afrontamiento que se utilizan para evitar el estrés incluyen el uso de drogas. Objetivo: evaluar la relación entre el uso de drogas (alcohol, tabaco y cannabis) y el cumplimiento de las pautas de seguridad. Método: la asociación entre las variables se evaluó a través de cuestionarios que indicaban el cumplimiento de las pautas de seguridad y el consumo de drogas, 475 participantes mexicanos $(56.5 \%$ mujeres y $43.4 \%$ hombres) completaron el estudio. Resultados: los resultados sugieren que la mayoría de los participantes presentaba niveles bajos de abuso de drogas antes y durante el aislamiento. Hubo una disminución significativa en el consumo de tabaco, alcohol y cannabis, tanto en mujeres como en hombres. Al analizar el seguimiento a las recomendaciones, el bajo consumo de alcohol se correlacionó con la escala de comportamiento de seguridad, mientras que el tabaco y el cannabis se correlacionaron con la escala de comportamiento preventivo. Discusión: la actual muestra de mexicanos no ha consumido drogas como afrontamiento ante el aislamiento social.
\end{abstract}

Palabras clave: alcohol, cannabis, COVID-19, tabaco, uso de drogas.

\footnotetext{
Correspondlng author:

Diana Mejía Cruz; telephone number: +52 (644) 410-09-00 ext. 2454; e-mail: diana.mejia@itson.edu.mx; postal address: calle 5 de Febrero 818 Sur, Col. Centro, C.P. 8500, Ciudad Obregón, Sonora, México

Recibido: 20 de enero de 2021

Aceptado: 18 de marzo de 2021

doi: 10.28931/riiad.2021.1.04
} 


\section{INTRODUCTION}

The World Health Organization (WHO, 2020) has established several strategies in response to the COVID-19 pandemic. In many countries, the strategies include social distance and isolation. Therefore, nearly all work and academic activities were switched from in-person to online. As a by-product of these new lifestyle conditions, there could be an increase in previously diagnosed psychopathologies, such as stress symptoms and other physical problems like tension and headache.

Some countries have turned to technology to combat possible adverse outcomes. They have developed creative tools for providing evaluation and support to their populations. (Cao et al., 2020; Ho et al., 2020; Li, Ge, et al., 2020; Li, Wang, et al., 2020; Qiu et al., 2020; Wang et al., 2020; Wong et al., 2020). One illustrative example was the Weibo social network platform, where nearly 17,865 people undergoing epidemiological containment in China received a psychological evaluation. The information collected using this instrument provided researchers with confirmation of increasing anxiety, depression, aggressiveness, and low life satisfaction rates (Li, Wang, et al., 2020). Similarly, Qiu and collaborators (2020) found in a sample of 52,730 people that $35 \%$ of the respondents experienced psychological distress.

The increase of these mental health disorders could generate indifference towards the recommended safety guidelines. For example, some studies have shown that people with low levels of stress have more greatly attended to the requirements of epidemiological containment strategies such as hand washing, use of mouth covers, avoiding touching their faces, individual-level distancing, and isolation (Ho et al., 2020; Li, Wang, et al., 2020; Li, Yang, et al., 2020). One of the main coping styles before the emergence of stress symptoms and derivatives of psychiatric disorders such as post-traumatic disorder is drugs use (Franken et al., 2001; McConnell et al., 2014). The use of drugs can, by itself, undermine the immune system of individuals in a population (Cook, 1998), which can lead to increasing levels of morbidity to contract a viral disease such as COVID-19. Few studies during the pandemic have explored drug use. Hochstatter et al. (2021) found people used the same proportion of alcohol, cannabis, and other illicit drugs before and during the pandemic. In contrast, Reinstadler et al. (2021) monitored drug consumption during the lockdown by analyzing wastewater in Europe. The results showed that people used the same proportion of caffeine, morphine, oxazepam, cotinine, lidocaine, and a reduction of codeine, acetaminophen, trimethoprim, amphetamine, MDMA, benzoylecgonine, and ethyl sulfate.

Since the quarantine establishment in Mexico (March 16), a few studies have had monitored alcohol, tobacco, and drug use during social isolation. This information is crucial to decrease any potential emergence of mental health disorders, psychological stress, and domestic violence. This research aimed to evaluate the relationship between risky drug use before and during social isolation and its correlation with COVID-19 safety guidelines adherence set by WHO. As previous results showed different levels of drug use between genders in Mexico (Villatoro-Velázquez et al., 2017), it was decided to analyze the data in the same way to consider gender effects.

\section{METHOD}

\section{Participants and design}

This study used a cross-sectional design and a snowball sampling strategy. All participants were recruited online through social media. The survey was designed and sent to participants using the Google forms platform. During data collection, the participants did not provide any personal information such as name or last names. An Id number was assigned to each participant to guarantee their anonymity. All the data was stored in a secured server to which only the principal investigator had access. Before starting, an informed consent was showed to the participants (see Appendix). Only those over 18 years old were recruited. If they agreed to participate, the survey started; otherwise, no information was collected. The recruited sample was living in several areas of different states in Mexico (México city $18.31 \%$, Guadalajara $25.26 \%$, Sonora $16.42 \%$, Aguascalientes $11.36 \%$, others 17 states $28.65 \%$ ). A total of 475 participants (56.5\% females and $43.4 \%$ males) completed the surveys. The average age of males was 33.23 years old $(S D=11.67)$, and females were 32.07 years old $(S D=10.95)$. The sample was: $25.89 \%$ married, $3.36 \%$ divorced, $2.73 \%$ separated, $57.05 \%$ single, $9.89 \%$ free union, $1.05 \%$ widowers.

\section{Instruments}

For the present study, we used a group of structured surveys that examined demographic information (e.g., gender, region, and age), days of use by week, the quantity of use by day, as well as safety and preventive behaviors related to COVID-19 safety guidelines adherence based on WHO (2020) recommendations. The scale was divided into two subscales, preventive and safety behaviors. The scale of preventive behaviors evaluated eight items related to safeguarding activities, such as "In the last week, I have regularly and thoroughly cleaned my hands with an alcohol-based hand rub or washed them with soap and water." The scale of safety behaviors eval- 
uated seven items related to social avoidance, such as "In the last week, I stayed away from crowded places." High scores in both scales implied following WHO rules.

The Alcohol, Smoking, and Substance Involvement Screening Test (ASSIST) was used to verify the risky use of alcohol, tobacco, and drugs. This instrument provides information about drug abuse. Scores matching 27 or above indicate drug dependence that requires intensive treatment, scores between 4 and 26 indicate brief intervention requirements, and scores among 0 to 3 denote no current drug abuse risk. In Mexico, the instrument showed concurrent validity through significant correlations between ASSIST scores and AUDIT scores ( $r=$ .50), Fagerström $(r=.61)$ and DAST-10 $(r=.30)$. The test presented reliability with significant intraclass correlation coefficients (ICC), ranging from .20 to .84 (Linage \& Lucio, 2013; WHO ASSIST Working Group, 2002).

\section{Procedure}

An anonymous survey was created using google forms. The study was carried out during the first four weeks of the social isolation in Mexico caused by COVID-19 (April 20, 2020 to May 21, 2020). After this time, the survey was closed.

The participants voluntarily agreed to be part of the study when they read the informed consent. The study's purpose was notified on the website, previous to access to the surveys. The procedures complied with the Declaration of Helsinki on Human participants regarding: 1) Privacy and confidentiality; 2) Informed consent; 3) Research registration and publication; 4) Dissemination of results. All the information was included in the survey. If the participants wanted to know more about alcohol, tobacco, and drug use, we provided them with a clinical psychologists' mail to resolve doubts or receive an orientation. The participants took, on average, about 30 minutes to respond to all the surveys.

\section{Data analysis}

Following data screening, frequencies, means, and standard deviations were calculated for all sample characteristics and questionnaire scores.

By gender, a paired sample t-test was used to evaluate differences for the variables: days of use, the quantity of use, and ASSIST scores before and during social isolation. A chi-squared test was used to evaluate differences among risk levels before and during COVID-19.

A correlation analysis (Pearson and Spearman) was used to explore the significant correlations among days of use, the quantity of use, the COVID-19 safety guidelines questionnaire, and the ASSIST scores (tobacco, alcohol, cannabis) by gender. Although the questionnaire included the use of other drugs such as cocaine, amphetamines, inhalants, tranquilizers, hallucinogens, opioids, the results are shown only in terms of tobacco, alcohol, and cannabis use. The results are presented as such because the ASSIST test indicated that less than $2.2 \%$ of the sample population were using other drugs. The data were analyzed with SPSS (Version 22.0).

\section{RESULTS}

The analysis of the ASSIST test before and during the social isolation revealed that the majority of participants had low levels of drug abuse for tobacco (73.6\%), alcohol (81.8\%), and cannabis (89.2\%). For each drug, a small percentage of the sample presented high-risk levels of drug use. The evaluation of risky drug use levels showed a statistically significant difference before and during COVID-19 (Tobacco: females $X_{(4)}^{2}=251.6, p=$ .000, males $X_{(4)}^{2}=200.9, p=.000$; Alcohol: females $X^{2}{ }_{(4)}=$ 239.0, $p=.000$, males $X_{(4)}^{2}=159.2, p=.000$; Cannabis: females $X_{(4)}^{2}=346.0, p=.000$, males $X_{(4)}^{2}=310.7, p=$ $.000)$. There was a reduction in high-risk use for each of the three drugs and an increase in low-risk use. The transition of this pattern held true for both females and males (see Table 1).

The variables ASSIST total score (females: $t_{(108)}=5.32$, $p=.000$; males: $\left.t_{(111)}=3.42, p=.001\right)$, days of use by week (females: $t_{(108)}=3.71, p=.000$; males: $t_{(111)}=3.76$, $p=.000$ ), and quantity of use (females: $t_{(108)}=3.24, p=$ .002 ; males: $\left.t_{(111)}=3.54, p=.001\right)$ disclose a significant reduction in the tobacco use for both genders. Regarding alcohol use, the results revealed a significant decline only in the ASSIST total (females: $t_{(108)}=2.05, p=.042$; males: $t_{(111)}=2.16, p=.033$ ) score for both genders. Finally, for the use of cannabis, we found a significant reduction in the quantity of use (females: $t_{(108)}=-2.62, p=.010$; males: $t_{(111)}$ $=2.25, p=.026$ ) for both genders (see Table 1 ).

Next, adherence to the WHO's COVID-19 safety guidelines were evaluated. The result of this test showed a low correlation between drug use and adherence to the COVID-19 safety guidelines. For tobacco, days of use (females preventive scale $r_{p}=.143, p=.019$; males safety scale $r_{p}=.196, p=.005$ ); quantity of tobacco (males preventive scale $r_{p}=-.141, p=.044$, safety scale $r_{p}=-.274$, $p=.000$ ); ASSIST total score (females preventive scale $r_{p}$ $=.152, p=.013$ ); and risk level (females preventive scale $r_{s}=.166, p=.006$ ). For alcohol, days of use (females safety scale $r_{p}=.174, p=.004$; males safety scale $r_{p}=$ $-.210, p=.002$ ); quantity of alcohol (males safety scale $r_{p}=-.212, p=.002$ ); ASSIST total score (females safety scale $r_{p}=-.188, p=.002$ ); and risk level (females safety scale $r_{s}=-.152, p=.012$, males preventive scale $r_{s}=$ $-.147, p=.035$ ). With cannabis, days of use (males pre- 
ventive scale $r_{p}=-.194, p=.005$; males safety scale $r_{p}$ $=-.214, p=.002$ ); quantity of alcohol (males preventive scale $r_{p}=-.284, p=.000$ ); ASSIST total score (males safety scale $r_{p}=-.183, p=.009$ ); and risk level (females preventive scale $r_{s}=.132, p=.030$, males preventive scale $r_{s}=-.137, p=.050$; see Table 2).

Table 1

Drug use before and during COVID 19, by gender

\begin{tabular}{|c|c|c|c|c|c|c|c|c|}
\hline & $\begin{array}{l}\text { Females } \\
M(S D) \text { o } \\
\%(N)\end{array}$ & & & & $\begin{array}{l}\text { Males } \\
M(S D) \text { o } \\
\%(N)\end{array}$ & & & \\
\hline & $N=269$ & & & & $N=206$ & & & \\
\hline Tobacco & $\begin{array}{l}\text { Before } \\
\text { COVID }\end{array}$ & $\begin{array}{l}\text { During } \\
\text { COVID }\end{array}$ & Statistics & $P$ & $\begin{array}{l}\text { Before } \\
\text { COVID }\end{array}$ & $\begin{array}{l}\text { During } \\
\text { COVID }\end{array}$ & Statistics & $P$ \\
\hline Low-risk & $73.6 \%(198)$ & $78.1 \%(210)$ & $251.61^{a}$ & .000 & $59.7 \%(123)$ & $62.1 \%(128)$ & $200.98^{a}$ & $<.001$ \\
\hline Moderate risk & $24.2 \%(65)$ & $20.8 \%(56)$ & & & $36.9 \%(76)$ & $35.9 \%(74)$ & & \\
\hline High-risk & $2.2 \%(6)$ & $1.1 \%(3)$ & & & $3.4 \%(7)$ & $1.9 \%(4)$ & & \\
\hline $\begin{array}{l}\text { ASSIST total } \\
\text { score }\end{array}$ & $5.1(7.5)$ & $4.4(6.7)$ & $5.32^{b}$ & .000 & $7.1(8.5)$ & $6.4(7.7)$ & $3.42^{b}$ & .001 \\
\hline $\begin{array}{l}\text { Days of use } \\
\text { per week }\end{array}$ & $0.73(1.7)$ & $0.52(1.6)$ & $3.71^{\mathrm{b}}$ & .000 & $1(2.09)$ & $0.75(1.9)$ & $3.76^{b}$ & $<.001$ \\
\hline $\begin{array}{l}\text { Quantity of } \\
\text { use per day }\end{array}$ & 2.09 (7.3) & $1.05(4.9)$ & $3.24^{b}$ & .002 & $3.4(10.8)$ & $1.7(6.3)$ & $3.54^{\mathrm{b}}$ & .001 \\
\hline \multicolumn{9}{|l|}{ Alcohol } \\
\hline Low-risk & $81.8 \%(220)$ & $82.5 \%(222)$ & $239.03^{a}$ & .000 & $78.6 \%(162)$ & $81.1 \%(167)$ & $159.23^{a}$ & $<.001$ \\
\hline Moderate risk & $17.1 \%(46)$ & $16.4 \%(44)$ & & & $18.9 \%(39)$ & $17 \%(35)$ & & \\
\hline High-risk & $1.1 \%(3)$ & $1.1 \%(3)$ & & & $2.4 \%(5)$ & $1.9 \%(4)$ & & \\
\hline $\begin{array}{l}\text { ASSIST total } \\
\text { score }\end{array}$ & $7.4(6.2)$ & $6.8(6.2)$ & $2.05^{b}$ & .042 & $8.1(6.9)$ & $7.4(7)$ & $2.16^{b}$ & .033 \\
\hline $\begin{array}{l}\text { Days of use } \\
\text { per week }\end{array}$ & $1.3(1.2)$ & $1.2(1.5)$ & $-0.64^{b}$ & .523 & $1.6(1.6)$ & $1.3(1.7)$ & $.894^{b}$ & .373 \\
\hline $\begin{array}{l}\text { Quantity of } \\
\text { use per day }\end{array}$ & $2.9(4.1)$ & $2.1(3.3)$ & $1.82^{b}$ & .071 & $3.4(4.9)$ & $2.5(4)$ & $1.28^{b}$ & .203 \\
\hline \multicolumn{9}{|l|}{ Cannabis } \\
\hline Low-risk & $89.2 \%(240)$ & $88.5 \%(238)$ & $346.05^{a}$ & .000 & $79.1 \%(163)$ & $81.1 \%(167)$ & $310.73^{a}$ & $<.001$ \\
\hline Moderate risk & $9.7 \%(26)$ & $10.8 \%(29)$ & & & $18.9 \%(39)$ & $16 \%(33)$ & & \\
\hline High-risk & $1.1 \%(3)$ & $0.7 \%(2)$ & & & $1.9 \%(4)$ & $2.9 \%(6)$ & & \\
\hline $\begin{array}{l}\text { ASSIST total } \\
\text { score }\end{array}$ & $2.2(4.7)$ & $2.3(5)$ & $-1.28^{b}$ & .201 & $4.06(6.9)$ & $3.96(7.1)$ & $.805 b$ & .422 \\
\hline $\begin{array}{l}\text { Days of use } \\
\text { per week }\end{array}$ & $0.35(1.1)$ & $0.45(1.4)$ & $1.33^{b}$ & .186 & $0.87(1.9)$ & $0.79(1.9)$ & $1.02^{b}$ & .310 \\
\hline $\begin{array}{l}\text { Quantity of } \\
\text { use per day }\end{array}$ & $1.2(7.4)$ & $0.93(5.3)$ & $-2.62^{b}$ & .010 & $4.07(15.2)$ & $2.40(9.4)$ & $2.25^{b}$ & .026 \\
\hline
\end{tabular}


Table 2

Correlation between drug use and adherence to COVID-19 safety guidelines

\begin{tabular}{|c|c|c|c|c|}
\hline & \multicolumn{2}{|c|}{ Females $N=269$} & \multicolumn{2}{|c|}{ Males $N=206$} \\
\hline During COVID-19 & \multicolumn{2}{|c|}{ COVID-19 Scale } & \multicolumn{2}{|c|}{ COVID-19 Scale } \\
\hline Tobacco & $\begin{array}{l}\text { Preventive } \\
\text { Behavior }\end{array}$ & $\begin{array}{c}\text { Safety } \\
\text { Behavior }\end{array}$ & $\begin{array}{l}\text { Preventive } \\
\text { Behavior }\end{array}$ & $\begin{array}{c}\text { Safety } \\
\text { Behavior }\end{array}$ \\
\hline Risk level & $.166^{\star b}$ & $.099^{b}$ & $.052^{\mathrm{b}}$ & $.003^{b}$ \\
\hline Days of use per week & $.143^{\star a}$ & $.042^{\mathrm{a}}$ & $-.079^{a}$ & $-.196^{\star a}$ \\
\hline Quantity of use & $.053^{\mathrm{a}}$ & $-.029^{a}$ & $-.141^{\star a}$ & $-.274^{\star a}$ \\
\hline ASSIST total score & $.152^{\star a}$ & $.080^{\mathrm{a}}$ & $.021^{a}$ & $.064^{a}$ \\
\hline \multicolumn{5}{|l|}{ Alcohol } \\
\hline Risk level & $.000^{\mathrm{b}}$ & $-.152^{\star b}$ & $-.147^{\star \mathrm{b}}$ & $-.112^{b}$ \\
\hline Days of use per week & $-.057^{a}$ & $-.174^{\star a}$ & $-.104^{a}$ & $-.210^{\star a}$ \\
\hline Quantity of use by day & $-.039 a$ & $-.110^{\mathrm{a}}$ & $-.108^{a}$ & $-.212^{\star \mathrm{a}}$ \\
\hline ASSIST total score & $-.096^{a}$ & $-.188^{\star a}$ & $-.127^{a}$ & $-.133^{a}$ \\
\hline \multicolumn{5}{|l|}{ Cannabis } \\
\hline Risk level & $.132^{\star b}$ & $.005^{b}$ & $-.137^{\star b}$ & $-.115^{b}$ \\
\hline Days of use per week & $.072^{a}$ & $.016^{\mathrm{a}}$ & $-.194^{\star a}$ & $-.214^{\star a}$ \\
\hline Quantity of use by day & $.052^{\mathrm{a}}$ & $.052^{\mathrm{a}}$ & $-.284^{\star a}$ & $-.116^{a}$ \\
\hline ASSIST total score & $.091^{a}$ & $-.015^{a}$ & $-.100^{a}$ & $-.183^{\star a}$ \\
\hline
\end{tabular}

${ }^{*} P$ values $<.05,{ }^{a} r$ Pearson correlation coefficient, ${ }^{b} r$ Spearman correlation coefficient

\section{DISCUSSION}

The research results showed significant differences among the risky drug use levels before and during the COVID-19 social isolation between tobacco, alcohol, and cannabis. For both females and males, high-risk drug use levels were reduced, and low-risk consumption levels were increased. This discovery was unexpected as it contradicts stress literature findings that report an increase in drug use as a coping mechanism for stress symptomologies (Franken et al., 2001; McConnell et al., 2014). However, the results are concordant with other studies about drug use during the pandemic (Hochstatter et al., 2021; Reinstadler et al., 2021). Only $6.4 \%$ of the population reported tobacco-related problems; $2.2 \%$ of the sample populations showed alcohol dependency and only . $6 \%$ present addiction to other drugs. In contrast to females, males showed moderate and high-risk drug use levels, similar to the last national drug use survey (Villatoro et al., 2017). The low level of drug dependency could indicate that a high percentage of the population has coping styles other than drugs.

We found a similar decrease effect for the variable's days of use by week, the quantity of use by day, and the ASSIST total score in the three drugs, but the only significant difference was tobacco use. However, this finding is hard to interpret due to the associated limitations of the study. First, we did not include any scale to measure coping styles. Second, we did not include any scale to measure stress, which could have given us an idea of how drug abuse may correlate with stress symptoms, such as the Symptom Check List 90 (Cruz et al., 2004). However, we chose not to include these additional sections because people are more likely to drop out during extended periods. Nevertheless, it is possible that including an online reward could motivate the participants to finish long surveys.

To understand why the high-risk drug use levels were reduced and low-risk consumption levels were increased, we suggest exploring family dynamics. The current study 
only explored the civil status, such as previous studies during the pandemic (Hochstatter et al., 2021; Quu et al., 2020; Reinstadler et al., 2021). However, we did one analysis considering civil status and drug use. The results showed that the quantity of use by day of cannabis $\left(x^{2}=11.82, g l=5, p=.037\right)$ was different according to the civil status during the pandemic. The free union and single status were related with more quantity of use by day of alcohol and cannabis than the other status ( $p s<$ .05). Tobacco consumption was similar according the civil status ( $\left.X^{2}=6.44, g l=5, p=.265\right)$, as was alcohol's $\left(x^{2}=8.66, \mathrm{gl}=5, p=.123\right)$. These findings were not part of our objectives, but we consider that this variable could be related to the reduction of consumption. We suggest exploring it in further research.

The main limitation is connected to the sample size, which is not representative of the Mexican population, and not having a probabilistic sample due to COVID-19, so this study's results cannot be generalized. Furthermore, the type of analysis carried out not allows making causality claims.

Finally, we acknowledge that another weakness of the current research was the omission of stress scales used in previous studies (Cao et al., 2020; Ho et al.,2020; Li, Ge, et al., 2020; Li, Wang, et al., 2020; Qiu et al., 2020; Wang et al., 2020; Wong et al., 2020). Nevertheless, this is one of the few studies that explore the effects of drug use during the COVID-19 pandemic social isolation in Mexico. Our results showed that some proportion of the Mexican population in the studied cities had not increased tobacco, alcohol, and cannabis usage during the quarantine. The lower levels of risky drug use are related to satisfactory levels of adherence to the COVID-19 safety guidelines recommended by WHO. This correlation could be interpreted as in this Mexican sample, not using drugs as a coping style for social isolation.

\section{FUNDING}

This study received financial support from the Sonora Institute of Technology (PROFAPI_2020_0037) granted to DMC, and LAC; and through the CONACYT National Scholarship Program granted to AR (NSP: 291236, CVU: 592580).

\section{CONFLICT OF INTEREST}

The authors report no conflicts of interest.

\section{REFERENCES}

Cao, W., Fang, Z., Hou, G., Han, M., Xu, X., Dong, J., \& Zheng, J. (2020). The psychological impact of the COVID-19 epidemic on college students in China. Psychiatry research, 287, 112934. doi: 10.1016/j.psychres.2020.112934

Cook, R. T. (1998). Alcohol abuse, alcoholism, and damage to the immune system - a review. Alcoholism: Clinical and Experimental Research, 22(9), 1927-1942. doi: 10.1111/j.1530-0277.1998. tb05900.x

Cruz, C., López, L., Blas, C., Macis, L., \& Chávez, R. (2004). Datos sobre la validez y confiabilidad de la Symptom Check List 90 (SCL-90) en una muestra de sujetos mexicanos. Salud Mental, 28(1), 72- 81. https://www.redalyc.org/pdf/582/58212808.pdf

Franken, I. H., Hendriks, V. M., Haffmans, P. J., \& van der Meer, C. W. (2001). Coping style of substance-abuse patients: Effects of anxiety and mood disorders on coping change. Journal of clinical psychology, 57(3), 299-306. doi: 10.1002/jclp.1013

Ho, C. S., Chee, C. Y., \& Ho, R. C. (2020). Mental health strategies to combat the psychological impact of COVID-19 beyond paranoia and panic. Annals Academy Medicine Singapore, 49(1), 1-3.

Hochstatter, K. R., Akhtar, W. Z., Dietz, S., Pe-Romashko, K., Gustafson, D. H., Shah, D. V., Krechel, S., Liebert, C., Miller, R., El-Bassel, N., \& Westergaard, R. P. (2021). Potential Influences of the COVID-19 Pandemic on Drug Use and HIV Care Among People Living with HIV and Substance Use Disorders: Experience from a Pilot mHealth Intervention. AIDS and behavior, 25(2), 354-359. doi: 10.1007/s10461-020-02976-1

Li, Z., Ge, J., Yang, M., Feng, J., Qiao, M., Jiang, R., Bi, J., Zhan, G., Xu, X., Wang, L., Zhou, Q., Zhou, C., Pan, Y., Liu, S., Zhang, H., Yang, J., Zhu, B., Hu, Y., Hashimoto, K., Jia, Y., ... \& Yang, C. (2020). Vicarious traumatization in the general public, members, and non-members of medical teams aiding in COVID-19 control. Brain, behavior, and immunity, 88, 916-919. doi: 10.1016/j. bbi.2020.03.007

Li, S., Wang, Y., Xue, J., Zhao, N., \& Zhu, T. (2020). The impact of COVID-19 epidemic declaration on psychological consequences: a study on active Weibo users. International journal of environmental research and public health, 17(6), 2032. doi: 10.3390/ ijerph17062032

Li, W., Yang, Y., Liu, Z. H., Zhao, Y. J., Zhang, Q., Zhang, L., Cheung, T., \& Xiang, Y. T. (2020). Progression of Mental Health Services during the COVID-19 Outbreak in China. International journal of biological sciences, 16(10), 1732-1738. doi: 10.7150/ ijbs. 45120

Linage, M., \& Lucio, E. (2013). Propiedades psicométricas del ASSIST en un grupo de estudiantes mexicanos. Revista Española de drogodependencias, 1, 37-51.

McConnell, M. M., Memetovic, J., \& Richardson, C. G. (2014). Coping style and substance use intention and behavior patterns in a cohort of BC adolescents. Addictive behaviors, 39(10), 13941397. doi: 10.1016/j.addbeh.2014.05.018

Qiu, J., Shen, B., Zhao, M., Wang, Z., Xie, B., \& Xu, Y. (2020). A nationwide survey of psychological distress among Chinese people in the COVID-19 epidemic: implications and policy recommendations. General psychiatry, 33(2), e100213. doi: 10.1136/ gpsych-2020-100213 
Reinstadler, V., Ausweger, V., Grabher, A. L., Kreidl, M., Huber, S., Grander, J., Haslacher, S., Singer, K., Schlapp-Hackl, M., Sorg, M., Erber, H., \& Oberacher, H. (2021). Monitoring drug consumption in Innsbruck during coronavirus disease 2019 (COVID-19) lockdown by wastewater analysis. The Science of the total environment, 757, 144006. doi: 10.1016/j.scitotenv.2020.144006

Villatoro-Velázquez, J. A., Resendiz-Escobar, E., Mujica- Salazar, A., Bretón-Cirett, M., Cañas-Martínez, V., Soto-Hernández, I., Fregoso-Ito, D., Fleiz-Bautista, C., Medina-Mora, M. E., Gutiérrez-Reyes, J., Franco-Núñez, A., Romero-Martínez, M., \& Mendoza-Alvarado, L. (2017). Encuesta Nacional de Consumo de Drogas, Alcohol y Tabaco: Reporte de Drogas. Instituto Nacional de Psiquiatría Ramón de la Fuente Muñiz, Comisión Nacional Contra las Adicciones, Secretaría de Salud. https:// encuestas.insp.mx/ena/encodat2017/reporte_encodat_drogas_2016_2017.pdf
Wang, C., Pan, R., Wan, X., Tan, Y., Xu, L., Ho, C. S., \& Ho, R. C. (2020). Immediate psychological responses and associated factors during the initial stage of the 2019 coronavirus disease (COVID-19) epidemic among the general population in China. International journal of environmental research and public health, 17(5), 1729. doi: 10.3390/ijerph17051729

Wong, J. E., Leo, Y. S., \& Tan, C. C. (2020). COVID-19 in Singaporecurrent experience: critical global issues that require attention and action. Jama, 323(13), 1243-1244. doi: 10.1001/jama.2020.2467

WHO ASSIST Working Group. (2002). The Alcohol, Smoking and Substance Involvement Screening Test (ASSIST): development, reliability and feasibility. Addiction (Abingdon, England), 97(9), 1183-1194. doi: 10.1046/j.1360-0443.2002.00185.x

World Health Organization. (2020). Critical preparedness, readiness and response actions for COVID 19. https://www.who.int/emergencies/diseases/novel-coronavirus-2019/technical-guidance 


\section{APPENDIX}

\section{DRUG USE DURING THE PANDEMIC: ONLINE SURVEY INFORMATION AND CONSENT FORM}

You are invited to participate in the study "Drug use during the pandemic." The following information will describe your role as a potential participant in the online survey.

We recommend that you print this page and keep it for your records. If you cannot print a copy, you can request an electronic version by emailing: rodrigo.gutierrezt@ alumno.udg.mx. This form is only part of the process and should give you a basic idea of what the research is about and what your participation will entail. If you would like more details on something mentioned here or information not included, please ask us via email.

About this study:

The goal of this study is to understand better the impact of the COVID-19 pandemic on drug use. We are particularly interested in knowing the effect that social isolation has on drug use behavior. Our final objective is to use the information from this study to know the future impact on the population's health.

What will you participate in today?

You will complete a series of online questionnaires. The questions are related to the amount of alcohol, tobacco, and other drugs you regularly use.

This questionnaire considers substances that can be smoked, swallowed, inhaled, or injected. Some of these substances may be prescribed by a doctor (such as amphetamines, sedatives, and pain medications). Medicines prescribed by your doctor will NOT be recorded in this interview, but if you have taken these substances for reasons other than those prescribed or have taken them more often or in higher doses than prescribed, please indicate so.

The present study considers questions about illegal drugs. However, YOU MUST KNOW that all information will be STRICTLY CONFIDENTIAL.

The average response time is between 30 and 40 minutes. Do I have to participate?
Participation in this online survey is voluntary, and you can terminate your participation at any time without penalty. If you start the survey and do not want to continue, you can exit the browser.

How will your confidentiality be protected?

The data collected today will be stored on a private server that only the principal investigator can access. Upon receipt of their information, all participants will be assigned an anonymous code number. All data will remain confidential and will only be linked to an arbitrary participant ID.

We will write articles and make presentations using the information from this project for scientific purposes only, and we will never use names that can identify anyone in the study.

All copies of the identifiable data collected will be deleted and/or destroyed within five years after collection (before May 30, 2025). An unidentified data file, which will only include unidentified survey responses, will be stored indefinitely.

What are the possible benefits and risks?

Some of the questions may remind you of recent challenging experiences, which can sometimes provoke negative emotions. You do not have to answer any questions that make you feel uncomfortable.

There are no direct benefits to you for participating. However, it will help greatly to raise awareness of the potential health effects of the pandemic.

What will be done with the results of this survey?

This study will assess whether there is a risk associated with drug use and develop appropriate resources to help people cope with stress during the COVID-19 outbreak. If you would like a summary of the research results, we will ask you to check a box to indicate how you wish to receive this information (for example, by email or in-person). We expect the results of the survey to be available around March 2021. The results will be presented in publications and theses. 